Article

\title{
Investigation of the Mechanical and Electromechanical Starting Characteristics of an Asynchronous Electric Drive of a Two-Piston Marine Compressor
}

\author{
Sergei G. Chernyi ${ }^{1,2,3, * \mathbb{D}}$, Pavel Erofeev ${ }^{1}$, Bogdan Novak $^{1}$ and Vitalii Emelianov ${ }^{4}$ \\ 1 Department of Ship's Electrical Equipment and Automatization, Kerch State Maritime Technological \\ University, 298309 Kerch, Russia; pavel.erofeev.95@mail.ru (P.E.); bogdan.ds194@gmail.com (B.N.) \\ 2 Department of Cyber-Physical Systems, St. Petersburg State Marine Technical University, \\ 190121 Saint-Petersburg, Russia \\ 3 Department of Complex Information Security, Admiral Makarov State University of Maritime and Inland \\ Shipping, 198035 Saint-Petersburg, Russia \\ 4 Business Informatics Department, Financial University under the Government of the Russian Federation, \\ 49 Leningradsky Prospekt, 125993 Moscow, Russia; v.yemelyanov@gmail.com \\ * Correspondence: sergiiblack@gmail.com
}

Citation: Chernyi, S.G.; Erofeev, P.; Novak, B.; Emelianov, V.

Investigation of the Mechanical and Electromechanical Starting Characteristics of an Asynchronous Electric Drive of a Two-Piston Marine Compressor. J. Mar. Sci. Eng. 2021, 9, 207. https://doi.org/10.3390/ jmse9020207

Academic Editor: Alessandro Ridolfi Received: 21 December 2020

Accepted: 11 February 2021

Published: 17 February 2021

Publisher's Note: MDPI stays neutral with regard to jurisdictional claims in published maps and institutional affiliations.

Copyright: (c) 2021 by the authors. Licensee MDPI, Basel, Switzerland. This article is an open access article distributed under the terms and conditions of the Creative Commons Attribution (CC BY) license (https:// creativecommons.org/licenses/by/ $4.0 /)$.
Abstract: In the article, the mechanical and electromechanical starting characteristics of an asynchronous electric drive of a two-piston ship compressor are investigated by a numerical method. A distinctive feature of the operation of the electric drive of a reciprocating compressor is that its load torque changes with a certain frequency. The dependence of the load torque on the shaft of the electric drive of the piston compressor on the angle of rotation is presented in the form of a Fourier series. Moments of inertia are reduced to a single system that performs a rotary motion. Mechanical and electromechanical starting characteristics are constructed. The estimation of the degree of torque pulsations on the shaft is made. It is determined that the compressor has a large amplitude of torque ripple on the shaft, which, in turn, affects the magnitude of the current ripple in the electric drive.

Keywords: electric drive; compressor; piston; torque; maritime

\section{Introduction}

Refrigeration compressors designed to operate over a wide range of suction and discharge pressures are considered multi-purpose. These are compressors for single-stage refrigeration machines. In marine air conditioning systems, piston compressors are most often used. However, sometimes when refrigerating capacities are very high, centrifugal ones are also used. Owing the fact that the capacity of refrigerated holds can be hundreds of kilowatts, an increase in efficiency even by a few percent will lead to enormous savings [1].

Compressor efficiency is influenced by a large number of factors such as environment condition (humidity, temperature), the quality of mechanical parts, the quality of the coolant and vibrations as well as the efficiency of the drive motor. Therefore, it is possible to improve the efficiency of the ship's refrigeration unit by reducing the power consumption of the compressor drive motor [2-4]. Three-phase asynchronous electric motors with a short circuit rotor are often such motors.

The authors of the article [5] developed a dynamic model of a two-stage piston compressor driven by an asynchronous motor. This model is described as a rigid system consisting of a piston, rod, crosshead, connecting rod and crankshaft. Based on the equations of Newton and Euler, the loads acting on the crankshaft were calculated. The mass and inertia of these components as well as the thermodynamic cycle were the main parameters of this model. The simulation results showed that high torque amplitudes were generated due to the high pressure of the compressed gas. In the constant mode, the loads were in good agreement with the experimental data. The study showed the need to 
take into account the influence of load torque surges in the design and improvement of compressor units.

The authors of article [6] also investigated possible ways to improve the efficiency of compressor units. They developed an Excel program to calculate the required torque of a hermetic compressor taking into account gas force, component inertia and frictional resistance. It was noted that $90 \%$ of the total torque was required to overcome the gas force, $9 \%$ for inertia and $1 \%$ was lost for friction. To reduce the required torque and improve the starting performance, various methods were studied and the offset cylinder method was implemented.

In article [7] the authors constructed and investigated the starting characteristics of the electric drive of a four-piston compressor of a ship refrigeration unit using a mathematical model of an unbalanced load moment. The dependence of the load on the shaft of the electric drive of a piston compressor on the rotation angle was presented in the form of a mathematical model. Transient plots for speed and current were plotted for different values of the moment of inertia of the motor and flywheel. Numerical modeling showed that the start of an asynchronous motor without a flywheel with an unbalanced periodic load was carried out within the nominal values but in the steady-state operating mode, significant current ripples of more than $10 \%$ were observed.

Asynchronous electric motors consume a great amount of energy in starting modes. Thus, in order to increase the efficiency of the plant, it is necessary to investigate the starting characteristics of an electric drive operating on a piston compressor [8,9].

The objective of the article is to determine the mechanical and electromechanical starting characteristics of an asynchronous electric drive of a double-piston ship compressor. To meet the set objective, the dependence between the load torque on the shaft of the ship's double-piston compressor and the angular movement of the shaft (time) of the electric motor is created. Based on the data obtained, the moment of inertia of a dual-mass crank system of a ship compressor is calculated. The mechanical and electromechanical starting characteristics are simulated using the basic law of motion.

\section{Construction of the Dependence between the Load Torque on the Compressor and the Angular Movement of the Motor Shaft}

The load torque of the piston compressor electric drive is a non-linear quantity due to the complex dynamics of the system. The compressor can be considered as a dual-mass system in which both translational and rotational movement are present [10-12].

To determine the load torque of the electric drive created by the compressor, it is necessary to take into account the geometric parameters of the piston machine (connecting rod length, crank radius and piston diameter), the translational nature of the piston movement and the change in pressure in the cavity from the crank angle.

Figure 1 shows a piston compressor. When the rotation angle of the crank mechanism $(\varphi)$ equals $180^{\circ}$ the piston is at the bottom dead center (BDC); when $\varphi=0^{\circ}$, the piston is at the top dead center (TDC). The basic formula for calculating the instantaneous value of the torque on the electric motor shaft in the compressor motor system is as follows [13]:

$$
T_{k}=P T_{1} r \pi D^{2} / 4
$$

where $P$ is the pressure in the cylinder, $\mathrm{Pa} ; r$ is the radius of the crank, $\mathrm{m} ; T_{1}$ is the coefficient of the unit torque for the piston mechanism and $D$ is the piston diameter, $\mathrm{m}$. 


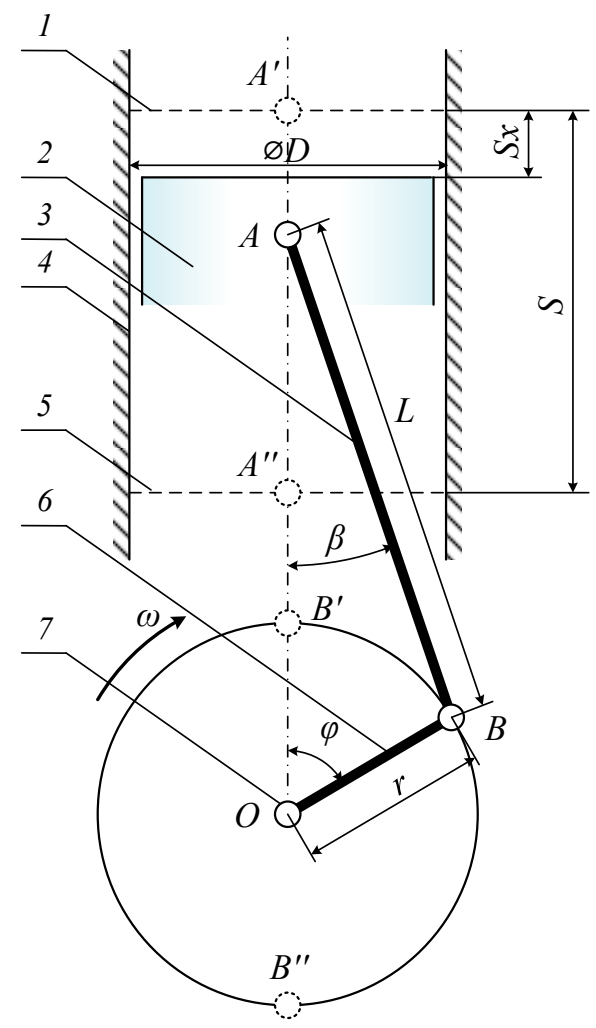

Figure 1. Diagram of a piston compressor: 1: top dead center (TDC), 2: piston, 3: connecting rod, 4: cylinder walls, 5: bottom dead center (BDC), 6: crank, 7: shaft.

The pressure in the cylinder is determined from the PV diagram depending on the volume of the gas being compressed.

The distance between the piston and the BDC changes according to the following law of variation [14]:

$$
S=r[(1-\cos (\omega t))+0.25 \lambda(1-\cos (2 \omega t))]
$$

where $\omega=\pi n / 30$ is an angular rotation speed of the crank, $\mathrm{c}^{-1} ; \lambda=r / \mathrm{L}$ is a dimensionless parameter of the crank mechanism and the ratio of the crank radius to the length of the connecting rod.

The unit torque coefficient for a piston mechanism is the torque created by the compressor on the piston with a force of $1 \mathrm{~N}$ and a crank radius of $1 \mathrm{~m}$ [15]:

$$
T_{1}=\sin (\omega t+\beta) / \cos (\beta)
$$

where $\beta$ is the angle of deflection of the connecting rod axis, rad.

The angle of deflection of the connecting rod relative to the axis of the piston stroke depends on the position and parameters of the crank mechanism [16]:

$$
\beta=\arcsin (\lambda \sin \varphi)
$$

Substituting Equations (2)-(4) into Equation (1), it is possible to find the load torque of the compressor on the electric motor shaft for one compressor cycle.

Figure 2 shows the PV diagram of a Bitzer 2CES-4Y-40S compressor for an R22 refrigerant at $\mathrm{T}=273 \mathrm{~K}$. Figure 3 shows the load torque of a compressor Bitzer 2CES-4Y-40S from the rotation angle of the electric motor in the form of tabulated values (1) and Fourier series (2). 


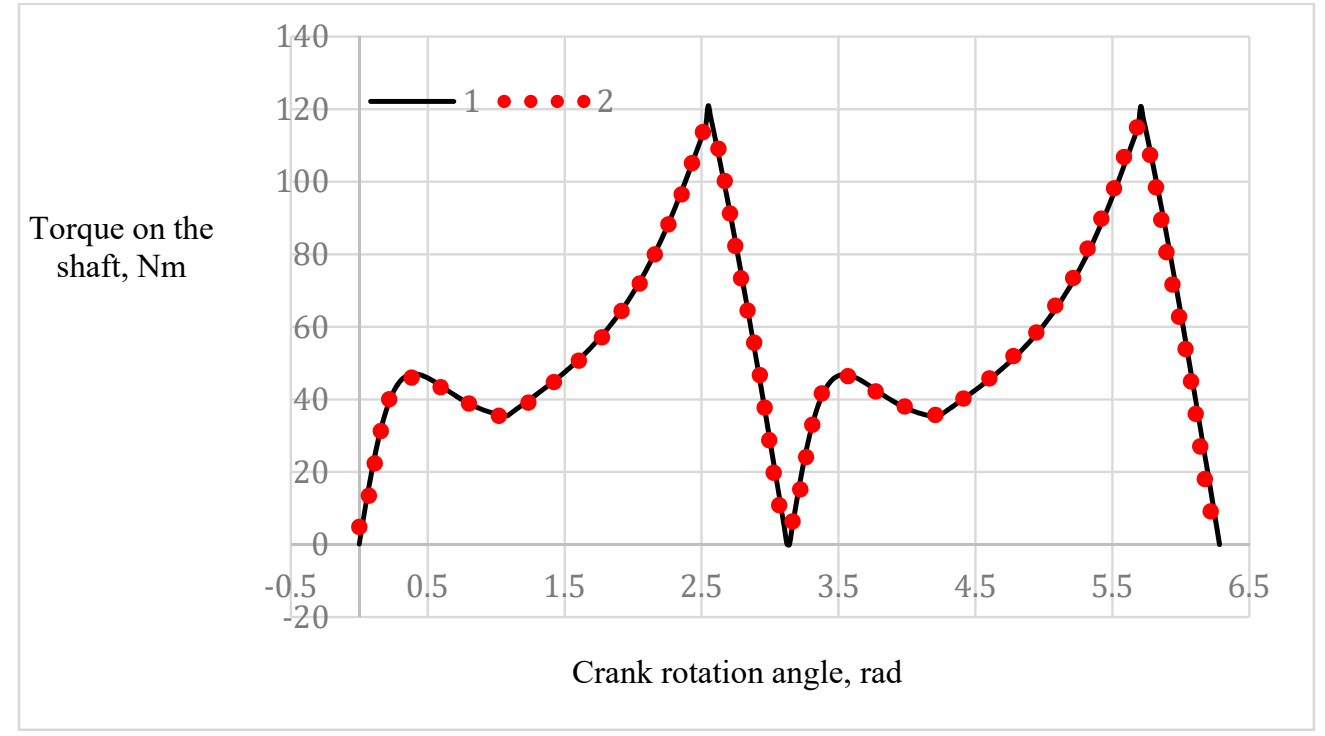

Figure 2. The calculated load torque of a double-piston compressor Bitzer 2CES-4Y-40S from the rotation angle of the electric motor in the form of tabulated values (1) and Fourier series (2).

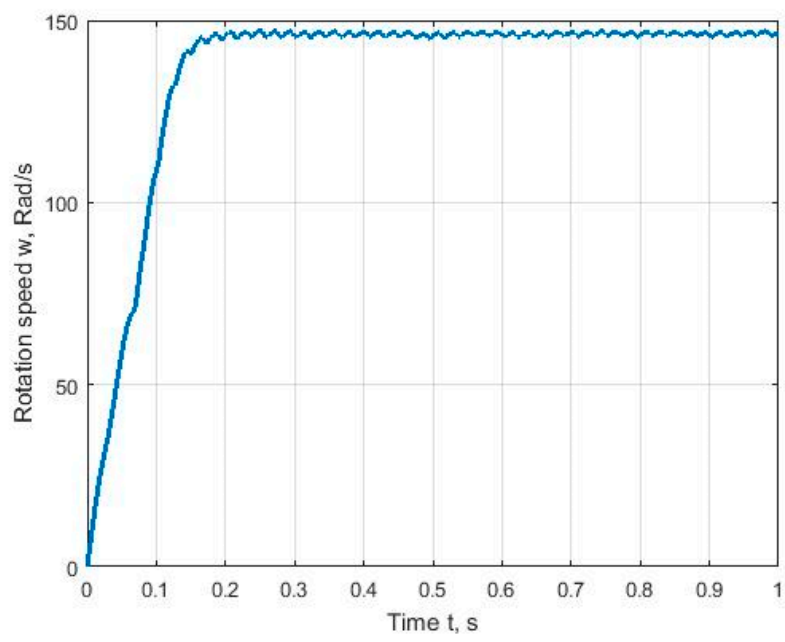

(a)

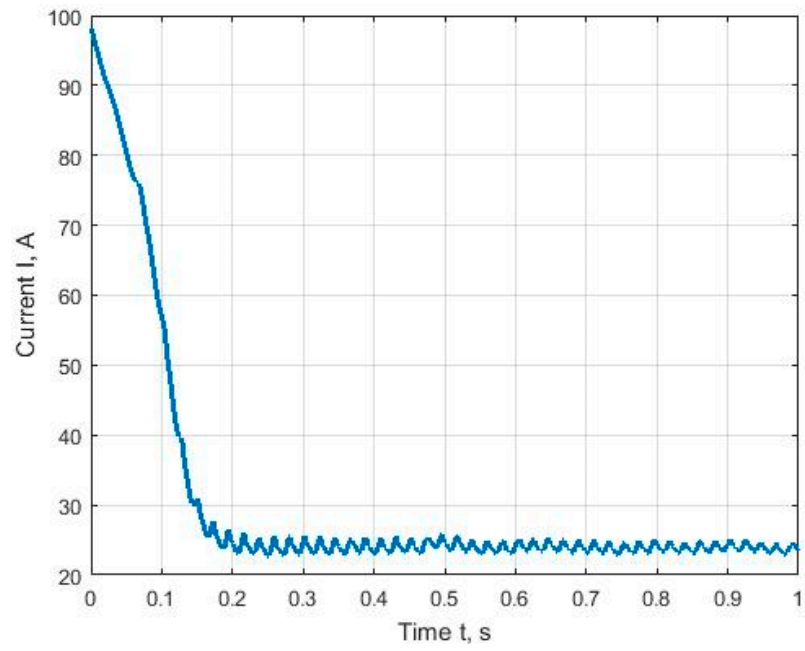

(b)

Figure 3. Change in rotation speed (a) and current (b) when starting an electric motor with a flywheel. 
The load torque for a ship double-piston compressor Bitzer2CES-4Y-40S was found with the parameters presented below in Table 1.

Table 1. Parameters of the Bitzer 2CES-4Y-40S compressor.

\begin{tabular}{cc}
\hline Parameters & Value \\
\hline Piston diameter & $55 \mathrm{~mm}$ \\
\hline Piston stroke & $39.3 \mathrm{~mm}$ \\
\hline Distance from BDC to the cover & $2 \mathrm{~mm}$ \\
\hline Overpressure & $32 \mathrm{bar}$ \\
\hline Coolant & $\mathrm{R} 134 \mathrm{a}$ \\
\hline Volume efficiency at & \\
\hline $1450 \mathrm{r} /$ min & $16.23 \mathrm{~m}^{3} / \mathrm{h}$ \\
\hline $1750 \mathrm{r} /$ min & $19.60 \mathrm{~m}^{3} / \mathrm{h}$ \\
\hline Protection index & $\mathrm{IP65}$ \\
\hline
\end{tabular}

\section{Mathematical Model and Decomposition.}

The obtained characteristic is presented in the form of a tabulated value and does not have a mathematical description, which makes it impossible to use in further calculations. Figure 2 shows that the obtained dependence was repeated with a certain periodicity. Thus, the obtained data could be replaced with an approximate mathematical model as a sum of harmonic functions [7-12]. To do this, we used the Fourier numerical decomposition. The load torque on the shaft was presented as follows (Figure 2):

$$
\begin{gathered}
T_{S t}(\varphi)=54.8149+27.4725 \sin (2 \varphi-2.9982)+18.7092 \sin (4 \varphi-1.6947)+ \\
+14.4583 \sin (6 \varphi-1.2194)+6.9396 \sin (8 \varphi-0.8621)+2.6316 \sin (10 \varphi-0.6688)+ \\
+1.4226 \sin (12 \varphi-1.7994)+1.9387 \sin (14 \varphi-1.9361)+1.978 \sin (16 \varphi-1.4877)
\end{gathered}
$$

The standard deviation for the period of Formula (5) from the dependence shown in Figure 2 (1) was 0.9981, which is permissible for use in electromechanics [10-12].

To study the asynchronous motor of the compressor, an asynchronous electric motor BA132M4 was selected, with the parameters presented in Table 2.

Table 2. Parameters of the motor BA132M4.

\begin{tabular}{cc}
\hline Parameter & Value \\
\hline Type & BA132M4 \\
\hline Rated power & $11 \mathrm{~kW}$ \\
\hline Rotation rate & $1445 \mathrm{r} / \mathrm{min}$ \\
\hline Rated current & $22.2 \mathrm{~A}$ \\
\hline Maximum torque coefficient & 3.2 \\
\hline Starting torque coefficient & 2.3 \\
\hline Starting current coefficient & 7.5 \\
\hline
\end{tabular}

The study of the starting characteristics of the drive motor was carried out using a mathematical model. The plotting of the graphics of changes in the rotation speed and starting current when starting the electric drive was performed for different values of the moments of inertia on the shaft. The graphics could be plotted either without using a flywheel or with a flywheel of a constant and variable moment of inertia. 
We then calculated the mechanical characteristics of an asynchronous electric drive of a double-piston ship compressor using the Kloss formula [9-11]:

$$
T=\frac{2 \cdot T_{\max }}{\frac{s}{s_{c}}+\frac{s_{c}}{s}}
$$

where $T$ was the moment on the motor shaft, $\mathrm{N} \cdot \mathrm{m} ; T_{\max }$ was the critical torque of the electric motor, $\mathrm{N} \cdot \mathrm{m} ; s$ was the slip and $s_{c}$ was the critical slip of the electric motor.

The basic equation of the rotational motion dynamics is [2-8]:

$$
\frac{d^{2} \varphi}{d t^{2}}=\frac{1}{J}\left(T-T_{S t}\right) ; \omega=\frac{d \varphi}{d t} .
$$

According to the adopted dual-mass system, the inertial forces of the moving masses were reduced to two forces. The first one was the inertia force of the piston masses $\left(P_{j}\right)$ and the second was the centrifugal inertia force of the rotating masses $\left(K_{r}\right)$.

For the central crank mechanism, the inertia force of piston masses was determined as the product of the mass $(\mathrm{mj})$ and the piston acceleration with the sign reversed according to the formula:

$$
P_{j}=-m_{j} j_{\Pi}=-m_{j} r \omega^{2}(\cos \varphi+\lambda \cos 2 \varphi)=P_{j 1}+P_{j 2} .
$$

Thus, the inertial force $\left(P_{j}\right)$ could be represented as the sum of the first and second order inertia forces, which varied according to the harmonic law depending on the crank angle. The main extreme values of the inertia force $\left(P_{j}\right)$, as well as the piston acceleration $\left(j_{p}\right)$, were at TDC and BDC. At TDC, the absolute value of the inertia force reached a maximum and at BDC, a minimum.

$$
P_{j \max }=C(1+\lambda) ; P_{j \min }=C(1-\lambda) .
$$

The inertia forces of the piston masses $\left(P_{j}\right)$ in the crank mechanism were presented as the free force $\left(P j^{\prime}\right)$ (Figure 2), which acted along the cylinder axis and was equal to the force $(P j)$, variable with respect to the magnitude and sign.

The connecting rod performed a complex plane-parallel movement in a plane perpendicular to the crankshaft axis. To determine the moment of inertia of the crankshaft, it was necessary to subtract the moment of inertia of the crankshaft nose and half of the moment of inertia of the crank journal from the value of $J_{e}$, which could be found by calculation.

The moment of inertia of the knee with the crankshaft nose was determined by the formula:

$$
J_{e}=\frac{T^{2} a^{2} m g}{16 \pi^{2} l}+m B^{2}
$$

where $a$ was the distance between the threads; $m$ was the mass of the part; $l$ was the length of threads; $B$ was the displacement of the center of gravity and $g$ was the acceleration of gravity.

The moment of inertia of the crankshaft nose was [5-9]:

$$
J_{n}=\frac{\pi d_{n}^{4}}{32} l_{n} \rho
$$

where $d_{n}$ was the diameter of the crankshaft nose, $\mathrm{m}$; $l_{n}$ was the crankshaft nose length, $\mathrm{m}$ and $\rho$ was the density of the steel, $\mathrm{kg} / \mathrm{m}^{3}$.

The moment of inertia of half of the crank journal was:

$$
J_{k 2}=\frac{1}{2} \frac{\pi d_{k}^{4} l_{k} \rho}{32} .
$$


where $d_{k}$ was the diameter of the crank journal, $\mathrm{m}$ and $l_{k}$ was the length of the crank journal, $\mathrm{m}$.

$$
J_{\text {cr.e }}=J_{e}-J_{n}-J_{k 2} \text {. }
$$

Without a crank portion of a shaft, its moment of inertia can be found by calculation [1-5]. The moment of inertia of the crank portion of a shaft when dividing it into four parts (two halves of the crank journal and the connecting rod journal without a counterweight and with a counterweight) was defined by the formula:

$$
J_{c r . p}=J_{k}+J_{s h 1}+J_{s h 2}+J_{s h}
$$

where $J_{k}=\frac{\pi d_{k}^{4}}{32} l_{k} \rho$, was the moment of inertia of the two halves of the crank journals; $J_{s h}$ was the moment of inertia of the connecting rod journal relative to the axis of the shaft rotation and $J_{s h 1}$ and $J_{s h 2}$ were the moments of inertia of the crankshaft web without a counterweight and with a counterweight.

When calculating the moment of inertia of a body relative to the axis of rotation parallel to the axis passing through the center of gravity and spaced from it at a distance $R$, the well-known transition formula was used [16]:

$$
J_{s h}=J \prime_{s h}+m_{s h} R^{2}=\frac{\pi d_{s h}^{4} l_{s h} \rho}{32}+\frac{\pi d_{s h}^{2} l_{s h} \rho R^{2}}{4}
$$

where $J^{\prime} s h$ was the moment of inertia of the connecting rod journal relative to the axis passing through the center of the shaft; $m_{s h}$ was the mass of the connecting rod journal, $\mathrm{kg}$; $R$ was the crank radius, $\mathrm{m} ; d_{s h}$ was the diameter of the connecting rod journal, $\mathrm{m}$ and $l_{s h}$ was the length of the connecting rod journal, $\mathrm{m}$.

The moment of inertia of the counterweight crank web could be found approximately by the formula:

$$
J_{s h 2}=J \prime_{s h 2}+m_{s h 2} a_{2}^{2}=\frac{h_{2} b_{\text {mean }}}{12}\left(h_{2}^{2}+b_{2}^{2}\right) l \rho+l h_{2} b_{\text {mean }} \rho
$$

where $J^{\prime}{ }_{\text {sh } 2}$ was the polar moment of inertia of the parallel piped mass relative to the axis passing through the center of gravity; $m_{s h 2}$ was the crank web mass, $\mathrm{kg}$ and $l, h_{2}$ and $b_{2}$ were the thickness, width and height of the crank web, kg.

We numerically solved the differential equation by the Runge-Kutta method of the Fourth Order using the following initial values: $\omega_{0}=0 \mathrm{Rad} / \mathrm{s} ; \varphi_{0}=0 \mathrm{Rad}$.

The electromechanical characteristic was based on the dependence of the motor current on the slip:

$$
I=\sqrt[2]{\frac{\left(d_{1} \cdot s^{2}+e_{1} \cdot s+F_{0}\right.}{s^{2}+\lambda \cdot s_{c} \cdot s+s_{c}^{2}}}
$$

where $I$ was the effective value of the current in the stator; $s$ was the slip; $\lambda$ was the overload capacity of the electric motor and $d_{1}, e_{1}$ and $F_{0}$ were the calculated coefficients for constructing the electromechanical characteristic [15].

To assess the starting characteristics of the piston compressor electric drive, we used the following indicators: the time of the transient process $T p$ and the relative magnitude of the speed and current ripple of the electric motor $(\Delta w$ and $\Delta I)$ in a steady-state:

$$
\begin{gathered}
\Delta w=\frac{w_{\max }-w_{\min }}{w_{\text {mean }}} 100 \% ; w_{\text {mean }}=\frac{w_{\max }+w_{\min }}{2} ; \\
\Delta I=\frac{I_{\max }-I_{\min }}{I_{\text {mean }}} 100 \% ; I_{\text {mean }}=\frac{I_{\max }+I_{\min }}{2} .
\end{gathered}
$$




\section{The Results of the Numerical Modeling}

Mathematical modeling of the start of an electric drive with a flywheel was carried out in Mathcad and made it possible to plot graphics of transient processes of the rotation speed and current of the electric motor during its start-up (Figure 3).

The graphics show that the start-up time $(T p)$ of the electric motor to the rated speed was $0.215 \mathrm{~s}$. Moreover, during the simulation, graphics of the speed and current pulsations were obtained in the steady-state operation of the electric drive under a periodically varying load (Figure 4).

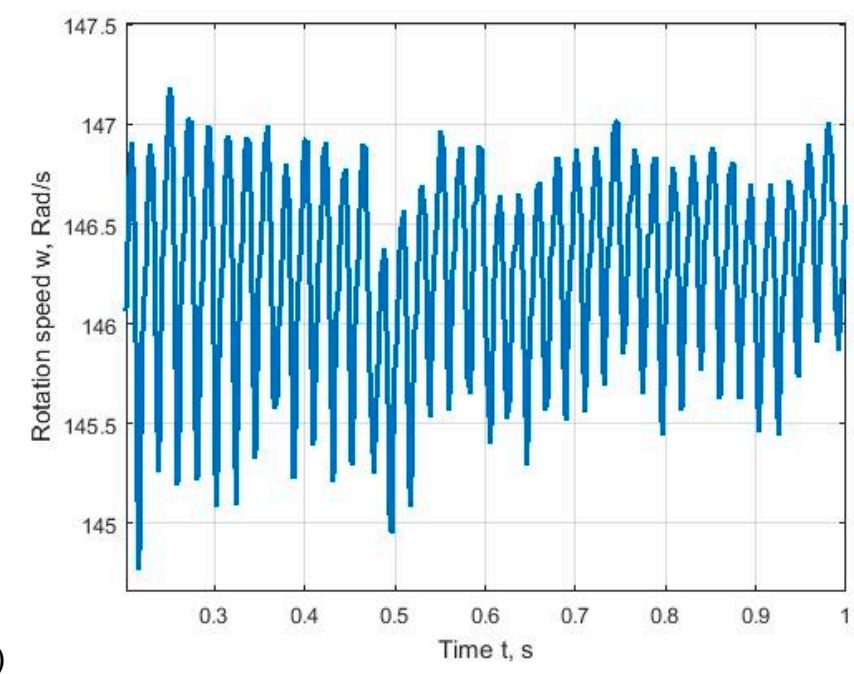

(a)

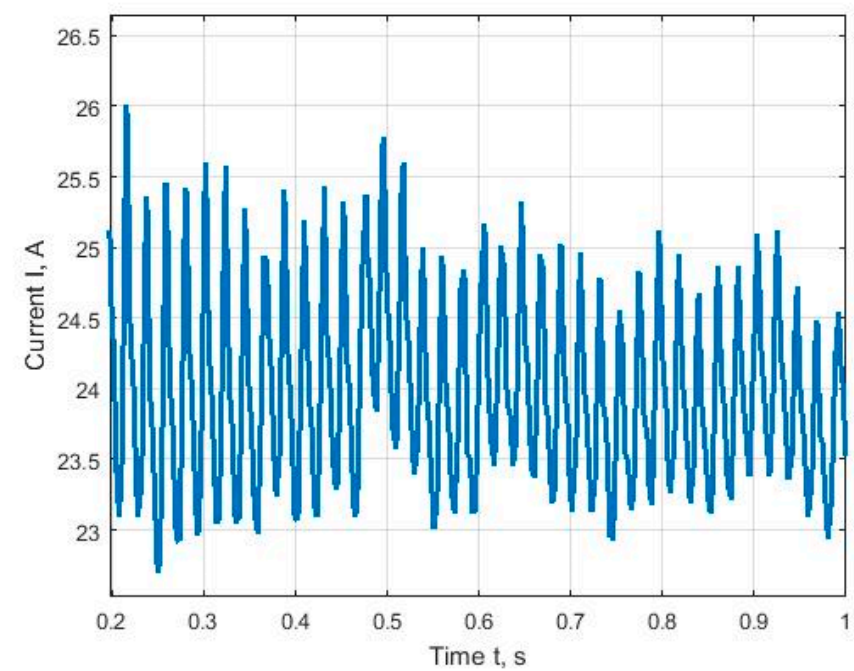

Figure 4. Ripple of speed (a) and current (b) in a steady-state with a flywheel.

The assessment of the pulsation degree was made according to Formula (9). The starting time and ripple data are listed in Table 3.

The ripples of the root mean square value of the current indicated the presence of current interharmonics in the piston compressor motor windings. To improve the efficiency of the electric drive, it was required to compensate for the detected current ripples. 
Table 3. Estimation of pulsations and starting time (Tp) of an electric drive with a flywheel.

\begin{tabular}{cc}
\hline Value & Quantity \\
\hline$T n$ & $0.115 \mathrm{c}$ \\
\hline$I_{\text {mean }}$ & $22.1 \mathrm{~A}$ \\
\hline$\Delta I$ & $5.714 \%$ \\
\hline$\omega_{\text {mean }}$ & $147.65 \mathrm{rad} / \mathrm{s}$ \\
\hline$\Delta w$ & $0.4 \%$ \\
\hline
\end{tabular}

With the existing ripples of the torque in the electric motor, proportional ripples of the stator electric current appeared. Ripple compensation was carried out using active filters or reactive power compensation. Depending on the load, the number of compressor pistons and the compressor motor rotation, the period of current and torque ripples in the overwhelming majority of cases would be a multiple of the fundamental harmonic thereby making it difficult to compensate. To reduce the ripple current for devices operating with a variable intermittent load such as compressors and pumps, it is advisable to use active harmonic filters with a fixed filtration or with an automatic adjustment of filtration parameters. The development of a device capable of a real-time compensation of a current ripple on the basis of the selected ripple will be a further study.

Listing and photo (Figure 5) of the program code for signaling identification [16] errors for ship equipment:

COMM ERR BETW. ACP/BR - ESU CAN A FAIL

COMM ERR BETW. ACP/BR - RPMU1 CAN A FAIL

COMM ERR BETW. ACP/BR - RPMU2 CAN A FAIL

COMM ERR BETW. ACP/BR - RAI CAN A FAIL

COMM ERR BETW. ACP/BR - DGU CAN A FAIL

COMM ERR BETW. ACP/BR - MEI CAN A FAIL

COMM ERR BETW. ACP/BR - C2LOC CAN A FAIL

COMM ERR BETW. ACP/BR - LTU BR CAN A FAIL

COMM ERR BETW. ACP/BR - LTU ECR CAN A FAIL

COMM ERR BETW. ACP/BR - PBT CAN A FAIL

COMM ERR BETW. ACP/BR - MPP ECR CAN A FAIL

COMM ERR BETW. ACP/BR - ACP-ECR CAN A FAIL

COMM ERR BETW. ACP/BR - RDO CAN A FAIL

COMM ERR BETW. ACP/BR - DGU SIO CAN A FAIL

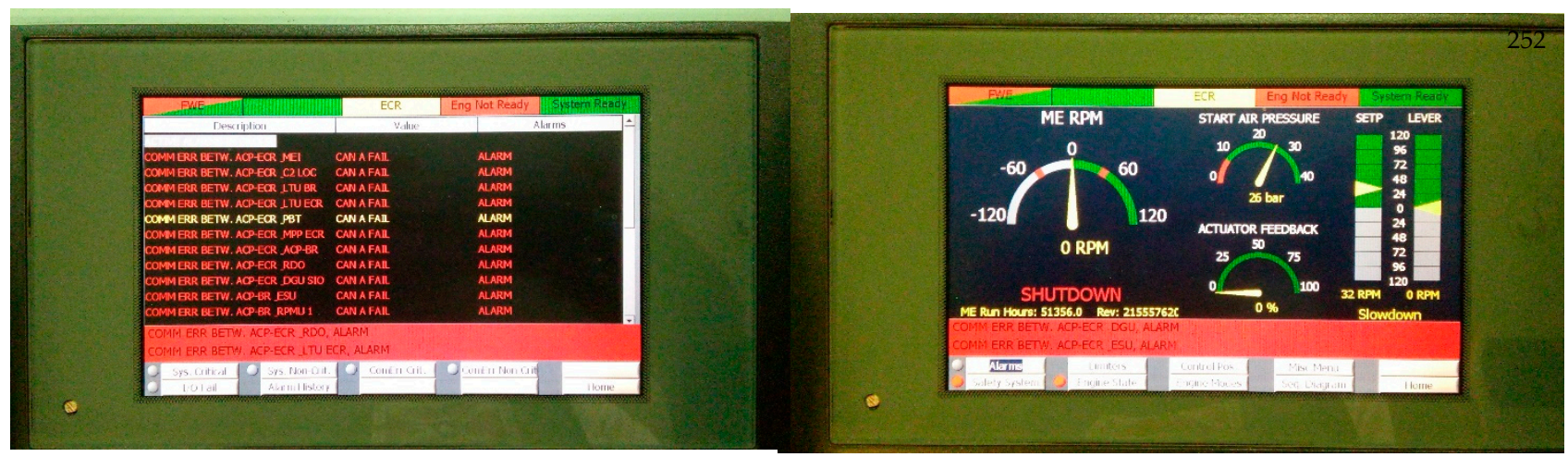

Figure 5. System error and crash monitor on ships (An example of errors presented on the ship's equipment for a service engineer).

As can be seen from Figure 5. the system also incorrectly set the servo motor setting. The telegraph knob was set to 0 and the system gave a setpoint of approximately 32 turns. 
This failure was associated with the desynchronization of the potentiometric sensor installed in the telegraph handle or a jump in the pulse current in the processing area of the CAN bus data.

To restore the correct operation of the system, it was necessary to calibrate the ECR LTU lever. The calibration algorithm is shown below. Calibration should be done with the engine stopped and blocked by start or by bridge command. With the engine running and the current lever in the command, any manipulations are prohibited.

\section{Conclusions}

A mathematical tool has been developed for determining the mechanical and electromechanical starting characteristics of the operation of an asynchronous electric wire of a piston compressor. The mathematical tool makes it possible to take into account the moment of inertia of the shaft and flywheel for calculating the start time of the electric motor and the effective values of the starting currents. The evaluation of the ripples of the selected compressor drive showed the permissible values of the start time of the electric motor. The results obtained for the current ripple in the motor windings made it possible to determine the direction of research for improving the efficiency of the compressor electric drives.

The article shows the calculation of the system load models. The parameters of the equipment and the state of the working process are given. The graphs are presented. A listing of control via a CAN bus control is presented.

Author Contributions: Conceptualization, S.G.C. and V.E.; methodology, S.G.C.; software, P.E.; validation, S.G.C., P.E. and B.N.; formal analysis, S.G.C.; resources, B.N.; data curation, B.N.; writingoriginal draft preparation, P.E.; writing-review and editing, S.G.C.; funding acquisition, S.G.C. All authors have read and agreed to the published version of the manuscript.

Funding: The research is partially funded by the Ministry of Science and Higher Education of the Russian Federation as part of the World-class Research Center program: Advanced Digital Technologies (contract No. 075-15-2020-903 dated 16.11.2020).

Conflicts of Interest: The authors declare no conflict of interest.

\section{References}

1. Vyngra, A.; Avdeyev, B. Calculation of the Load of an Electric Drive of a Reciprocating Compressor of a Ship Refrigeration Unit. In Proceedings of the IEEE International Multi-Conference on Industrial Engineering and Modern Technologies (FarEastCon), Vladivostok, Russia, 3-4 October 2018.

2. Sokolova, E.A.; Dzhioev, G.A. Development of an algorithm for automated enhancement of digital prototypes in machine engineering. In Proceedings of the IOP International Conference on Mechanical Engineering, Automation and Control Systems, Tomsk, Russia, 27-29 October 2017; pp. 012-037.

3. Žiravecka, A.; Gasparjans, A.; Terebkovs, A. Integrated mathematical model of ship electric compressor installations. In Maritime Transport and Infrastructure, Proceedings of the 13th International Conference, Riga, Latvia, 28-29 April 2011; Latvian Marine Academy: Riga, Latvia, 2011; pp. 186-191. ISSN 1691-3817.

4. Zhukov, V.; Masyutkin, E.; Avdeyev, B. The application of mathematical modeling for the development of devices as an example of viscous fluid purification from magnetic impurity. In IOP Conference Series: Materials Science and Engineering; IOP Publishing: Bristol, UK, 2017; no. 177, 012015.

5. Sokolov, S.; Glebov, N.; Novoselov, R.; Chernyi, S. Database problems of maritime transport industry on high load platform. MATEC Web Conf. 2018, 239, 03004. [CrossRef]

6. Dema, R.R.; Amirov, R.N.; Kalugina, O.B. Determining the parameters effecting the work of the lubricants supplying system at wide-strip hot rolling. In Proceedings of the 4th International Conference on Industrial Engineering, Moscow, Russia, 15-18 May 2019; No. 9783319956299. pp. 929-937.

7. Sokolov, S.; Zhilenkov, A.; Chernyi, S.; Nyrkov, A. Assessment of the Impact of Destabilizing Factors in the Main Engine Shaft of the Adaptive Speed Controller. Procedia Comput. Sci. 2018, 125, 420-426. [CrossRef]

8. Zhukov, V.A.; Sherban, S.A.; Melnik, O.V.; Sokolov, S.S.; Kolesnichenko, S.V. Improvement of methods and means of thermal control of ship power plants. In Proceedings of the 2019 IEEE Conference of Russian Young Researchers in Electrical and Electronic Engineering ELCONRUS, St. Petersburg and Moscow, Russia, 28-31 January 2019; pp. 389-392.

9. Chernyi, S. Techniques for selecting topology and implementing the distributed control system network for maritime platforms. AKCE Int. J. Graphs Comb. 2018, 15, 219-223. [CrossRef] 
10. Avdeev, B.; Dema, R.; Chernyi, S. Study and Modeling of the Magnetic Field Distribution in the Fricker Hydrocyclone Cylindrical Part. Computation 2020, 8, 42. [CrossRef]

11. Avdeev, B.; Vyngra, A.; Chernyi, S. Improving the Electricity Quality by Means of a Single-Phase Solid-State Transformer. Designs 2020, 4, 35. [CrossRef]

12. Avdeev, B.A.; Vyngra, A.V. Simulation of Variable Frequency Controlled AC Induction Motor Operating on Non-Linear Load. In Proceedings of the 2020 IEEE Conference of Russian Young Researchers in Electrical and Electronic Engineering (EIConRus), St. Petersburg and Moscow, Russia, 27-30 January 2020; pp. 2346-2349.

13. Vyngra, A.V.; Avdeyev, B.A.; Abdurakhmanov, R.F.; Yenivatov, V.V.; Ovcharenko, I.K. Mathematical Model of Start for a Piston Compressor Electric Drive of a Ship Refrigerator. In Proceedings of the 2019 IEEE Conference of Russian Young Researchers in Electrical and Electronic Engineering (EIConRus), St. Petersburg and Moscow, Russia, 28-31 January 2019; pp. 373-376.

14. Vyngra, A.V. Modeling the Operation of an Uninsulated DC-DC Converter as a Part of a Propeller Drive of Autonomous Underwater Vehicles. In Proceedings of the 2020 IEEE Conference of Russian Young Researchers in Electrical and Electronic Engineering (EIConRus), St. Petersburg and Moscow, Russia, 27-30 January 2020; pp. 2431-2434.

15. Sergei, C.; Aleksei, V.; Pavel, E.; Bogdan, N. Analysis of the Starting Characteristics of the Complex Maritime Systems. Procedia Comput. Sci. 2020, 167, 2164-2171. [CrossRef]

16. Chernyi, S.G.; Vyngra, A.V.; Novak, B.P. Physical modeling of an automated ship's list control system. J. Intell. Fuzzy Syst. 2020, 39, 8399-8408. [CrossRef] 